\title{
The Influence of Alkaline Treatment of Recycled Natural Materials on the Properties of Epoxy Resin Composites
}

\author{
Hamza M. Kamal* \\ Mohammed J. Kadhim** \\ Raeid K. Mohammed*** \\ *,**,*** Department of Materials Engineering/College of Engineering/Al-Mustansiriyah University/Baghdad \\ *Email: theengineer_1980@yahoo.com \\ ***Email: moh_materials@yahoo.com \\ **Email: raeid1980@uomustansiriyah.edu.iq
}

(Received 7 March 2018; accepted 17 May 2018)

https://doi.org/10.22153/kej.2018.05.003

\begin{abstract}
Natural fibers and particles reinforced composites are being broadly used due to their bio and specific properties such as low density and easy to machine and production with low cost. In this work, water absorption and mechanical properties such as tensile strength, flexural strength and impact strength of recycled jute fibers reinforced epoxy resin were enhanced by treating these fibers with alkaline solution. The recycled jute fibers were treated with different concentration of $(\mathrm{NaOH})$ solution at $\left(25^{\circ} \mathrm{C}\right)$ for a period of $(24)$ hours. From the obtained results, it was found that all these properties are improved when fibers treated with $(7.5 \mathrm{wt} \% \mathrm{NaOH})$ related to untreated fibers. Conversely, the mentioned properties of composites decreased after fibers treated with (10wt $\% \mathrm{NaOH})$. In addition, the hybrid composite with recycled jute fibers and recycled walnut shell powder showed obvious enhancement in the abovementioned properties.
\end{abstract}

Keywords: Alkaline treatment, composite, epoxy, jute fibers, walnut shell powders.

\section{Introduction}

Fabricated fibres such as carbon, glass and aramid have been utilized for many years in numerous applications varying from civil structures to aerospace industry. Due to the high cost of the materials and manufacturing methods for these man-made fibers, their wider used in several composite applications become limited. Therefore, there is a growing interest in the applying of the less expensive natural fibres and particles as reinforcement phase in composites field because of their lightweight, biodegradability, renewability and less health problems for the people producing the composites [1]. The effect of surface treatment of woven jute fabrics with silicone on stiffness and strength properties of Vinylester polymer are investigated by Basu, it was concluded that all these properties are slightly improved when compared with alkali treated [2]. Ratna and coworkers studied the effect of different natural fibers on the properties of polyester resin; it was observed that both of the tensile strength and modulus properties of jowar fibers is higher than those of sisal and bamboo fiber composites in their study [3].The effect of alkali (4-8\% by weight) treatment and elevated temperature $\left(40,80\right.$ and $\left.120{ }^{\circ} \mathrm{C}\right)$ on the mechanical properties of the bamboo fiber polyester composites are studied by Manalo, it was observed that the best mechanical properties that involved (bending, tensile and compressive strength and the stiffness) are increased by (7, 10, 81 and $25 \%$ respectively) higher than the untreated composites at $(6 \%)$ concentration of the alkaline solution. Also the tensile strength of bamboo composites are improved when tested up 
to $80{ }^{\circ} \mathrm{C}$ [4]. Libo Yan and coworkers studied the effect of alkali treatment on the microstructure and the mechanical properties of coir fibers reinforced polymer and cementitious composites, it was observed that alkali treatment improve the compressive stress and strain, flexural strength and the flexural toughness of coir fiber reinforced cementitious (CFRC) composites due to the improvement in fiber cement interfacial adhesion [5]. The bending behavior of natural sisal fiber reinforced polyester resin are studied with Munakaampe, the results show that the prepared composite exhibit better bending properties than the plain polymer matrix [6]. In addition, the impact strength of sisal fibers reinforced polyester is studied by Easwara Prasad and coworkers; it was found that, the (10) $\mathrm{mm}$ long sisal fibers treated for (24) hour is insufficient to improve the impact strength of sisal polyester composites [7]. Natural fibers have mechanical and physical properties that differs from fiber to fiber and due to its good mechanical properties such as the specific strength, addition with, non-abrasive, ecofriendly and the biodegradable characteristics, the natural fibers used as an alternative material for artificial fibers reinforced polymer. [8]

\section{Experimental Procedures \\ 2.1. Materials}

The raw materials used in this effort involves the epoxy resin with its hardener triethylene tetramine (TETA) as a matrix material and the jute fibers with walnut shell powders which used as a natural reinforcing materials for epoxy resin.

\section{1.a. Matrix material}

Epoxy resin with its hardener triethylene tetramine (TETA) (3:1) ratio (provided from SIROPOL.GP) are used as a matrix material due to its high modulus and strength, excellent chemical resistance, simplicity in processing and commercially available. In addition, the epoxy resins are unique among all thermosetting resins because of several factors including low cure shrinkage, compatibility with a great number of materials, strength and durability, adhesion, corrosion and chemical resistance, and electrical insulation [9]. Table (2-1) shows the properties of epoxy resin that used in this work.

\section{1.b. Reinforcing Materials}

In this work, two types of natural materials are used as reinforcing phases; the first is the jute fibers provided from jute sacks as shown in the (fig.1) with different weight fraction $(0,2.5,5$, 7.5 , and $10 \%$ ) respectively according to the following formula:

$\mathrm{W}_{\mathrm{f}}=\mathrm{w}_{\mathrm{f}} / \mathrm{w}_{\mathrm{c}}$

Where $\left(\mathrm{W}_{\mathrm{f}}\right)$ is the weight fraction of fibers, $\left(\mathrm{w}_{\mathrm{f}}\right)$ is the weight of fibers; $\left(\mathrm{w}_{\mathrm{c}}\right)$ is the weight of composite. Tables (2-2) and (2-3) show the composition and the mechanical properties of jute fibers. The latter is the walnut shell powder made from crushed walnut shell with $(5 \%)$ weight fraction. The main reasons from using these natural materials is ascribed to their biodegradable, non-toxic, recyclable, cheap and environmentally safe properties combined with the high tensile properties of the jute fibers related to other natural materials.

Table 2-1,

Mechanical properties of epoxy resin

\begin{tabular}{ll}
\hline Mechanical Property & Value \\
\hline Glass transition temperature & $120-130{ }^{\circ} \mathrm{C}$ \\
Tensile strength & $60-80 \mathrm{MPa}$ \\
Tensile Modulus & $3.5-4 \mathrm{GPa}$ \\
Elongation at break & $0.8 \%$ \\
Flexural strength & $55-65 \mathrm{MPa}$ \\
Compressive Strength & $170-182 \mathrm{MPa}$ \\
Density & $1.54 \mathrm{~g} / \mathrm{cm}^{3}$ \\
\hline
\end{tabular}

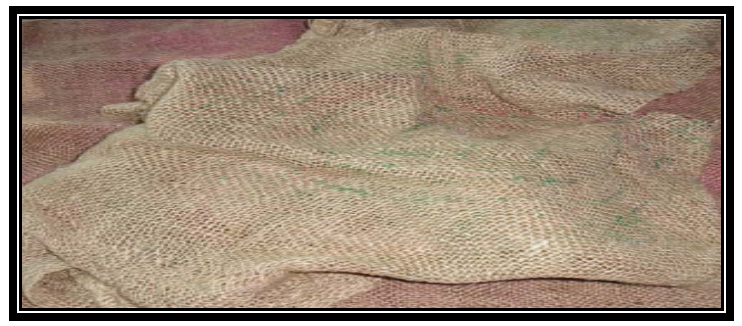

Fig.1. Jute sacks.

Table 2-2,

Chemical composition of jute fibers. [11]

\begin{tabular}{|lc|}
\hline Component & Content $(\%)$ \\
\hline Cellulose & 64.4 \\
Hemicellulose & 12.0 \\
Pectin & 0.2 \\
Lignin & 1.8 \\
Water soluble & 1.1 \\
Wax & 0.5 \\
Water & 10.0 \\
\hline
\end{tabular}


Table 2-3,

Mechanical properties of jute fibers. [11]

\begin{tabular}{|lllll|}
\hline $\begin{array}{l}\text { UTS } \\
\text { (MPa) }\end{array}$ & $\begin{array}{l}\text { Tensile } \\
\text { modulus } \\
\text { (GPa) }\end{array}$ & $\begin{array}{l}\text { Elongation } \\
(\%)\end{array}$ & $\begin{array}{l}\text { Specific } \\
\text { strength } \\
\text { (MPa) }\end{array}$ & $\begin{array}{l}\text { Specific } \\
\text { (GPa) }\end{array}$ \\
\hline $460-533$ & $2.5-13$ & 1.16 & 340 & 42.7 \\
\hline
\end{tabular}

\subsection{Alkaline treatment}

In order to enhance the morphology of the surface and the bonding properties of natural materials with epoxy resin, alkaline treatment are applied to these materials with $(7.5 \%$ and $10 \%)$ of $\mathrm{NaOH}$ solution for $(24 \mathrm{hr}$.) at ambient temperature. After that, the jute fibers and the walnut shell powders are washed with distilled water $(\mathrm{pH}=7)$ at room temperature to eliminate the alkali solution and then dried in oven at 70 ${ }^{\circ} \mathrm{C}$. Fig. 2 shows the natural materials that used in this work.



(a)

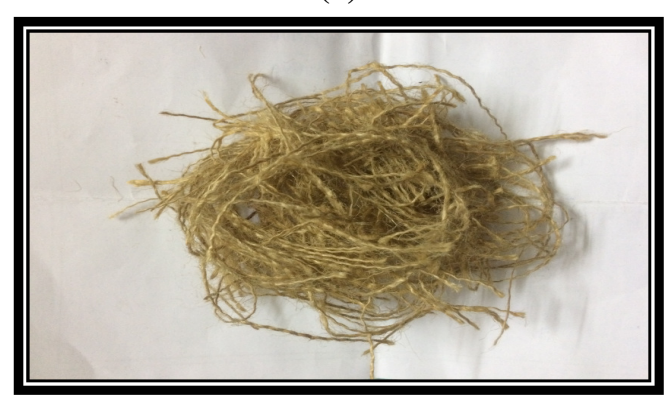

(b)

Fig. 2. Walnut shell powders (a), Jute fibers (b).

\subsection{Procedure}

By means of hand lay-up procedure, composite and hybrid composite materials are prepared in this work, in order to prepare the composite materials, the jute fibers are cut into short fibers with different length $(10,15$, and 20 $\mathrm{mm})$ respectively and then mixed with epoxy resin and its hardener for (3) minute with different weight fraction $(0,2.5,5,7.5$, and $10 \%)$ into a plastic cup until obtain a homogeneous mixture and then, the mixture poured into a wood mold for different dimensions according to American Society for Testing and Materials (ASTM) standards for each required test. The curing time taken by composites was (24) hr.

On the other hand, the hybrid composites are prepared by the same approach but by incorporating the best ratio of jute fibers that gives the best mechanical properties with $5 \%$ weight fraction of walnut shell powders inside epoxy matrix resin and examine its influences on the above-mentioned properties.

\section{Characterization}

In order to determine the required properties, three samples are prepared for each test by cutting the prepared composite and hybrid composite into the required geometry according to the ASTM standard and applied the procedures of each required test.

\subsection{Tensile Strength Measurements}

The tensile strength is measured based on the ASTM D3039 [12] specification by the universal testing machine at a strain rate of $10 \mathrm{~mm} / \mathrm{min}$. The geometry of the tensile test specimen with $(10 \%)$ weight fraction of jute fibers before machined shown in the fig.3.



(a)

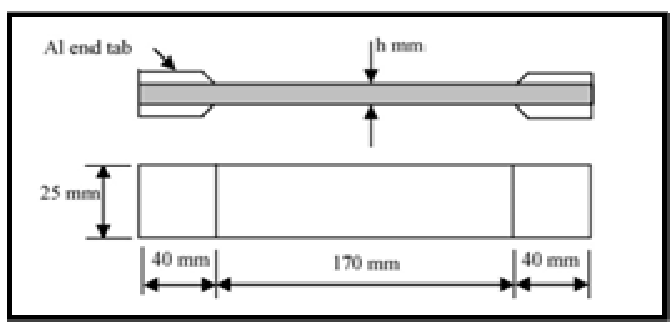

(b)

Fig. 3. Tension test geometry according to ASTM D3039. (a) Photo, (b) Schematic. 


\subsection{Impact Measurement}

The impact strength of the prepared composite determined by the Izod impact test according to ASTM standard D-256 [13]. The geometry of impact test specimen with (10\%) weight fraction of jute fibers shown in the fig.4.

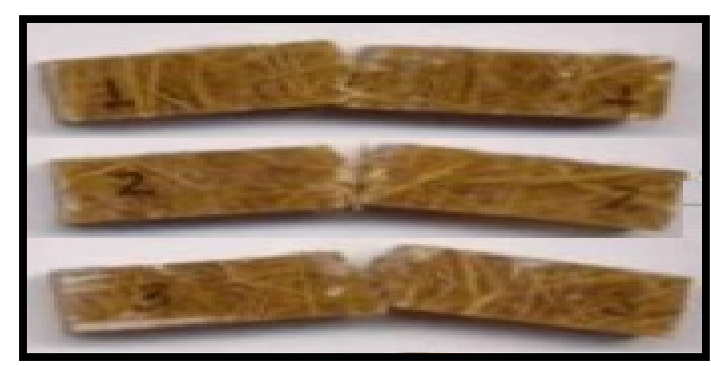

(a)

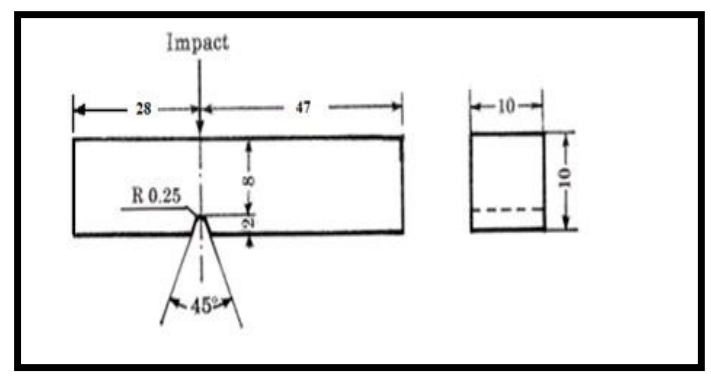

(b)

Fig. 4. Impact test geometry according to ASTM standard D-256. (a) Photo, (b) Schematic.

\subsection{Flexural strength measurement}

The flexural strength test is carried out according to the ASTM D790 [14] by using Universal Testing Machine with span length of (50) $\mathrm{mm}$ at the speed to $2 \mathrm{~mm} / \mathrm{min}$. The geometry of the flexural test specimen with $(10 \%)$ weight fraction of jute fibers shown in the fig.5.

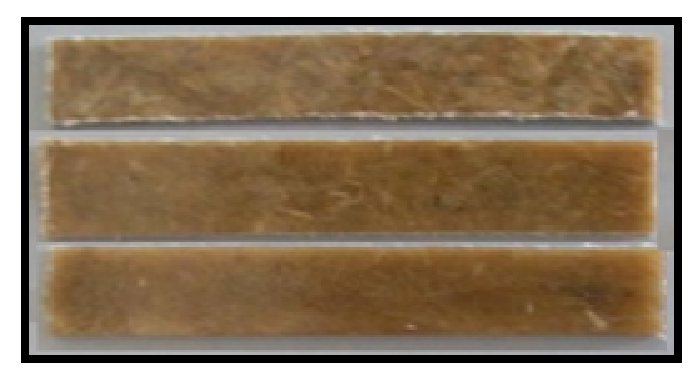

(a)

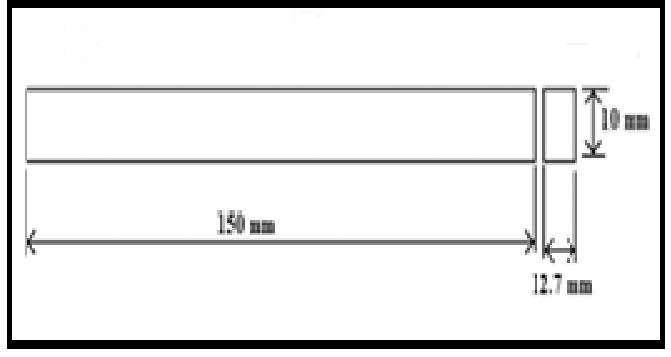

(b)

Fig. 5. Flexural test geometry according to the ASTM D790. (a) Photo, (b) Schematic.

\subsection{Water Absorption Measurement}

Water absorption measurement is determined by immersing the prepared composite specimens into distilled water at ambient temperature for about (24) hr. After that, the specimens remove from solution and wiped dry to remove the surface moisture. Then the specimens are weighted with digital scale in order to calculate the water absorption according to the following formula.

Water absorption $(\%)=[$ (wet weight-sample weight)/sample weight] ${ }^{*} 100$.

Where wet weight is the weight after immersing and sample weight is the weight before immersing.

\subsection{SEM Characterization}

SEM characterization type (TESCAN Vega II $\mathrm{XMU}$ ) is used in this work, which provides highresolution images. Separate at least three small samples from each specimen to ensure about homogeneity and unified structure. After that, the samples are cleaned, dried and finally mounted on a stub of metal with adhesive, coated with (40-60) $\mathrm{nm}$ of the gold due to its high conductivity and its relatively small grain size that enables very highresolution imaging.

\section{Results and Discussion}

The effects of untreated jute fibers with different weight fraction on the tensile, flexural and impact strength of epoxy resin are shown in fig.6, fig.7 and fig.8. It was found from the obtained results, all these properties are slightly enhanced when reinforced with untreated jute fibers and this enhancement increased with increasing the weight fraction of the fibers. 




Fig. 6. Tensile strength verses weight fraction of untreated jute fibers.

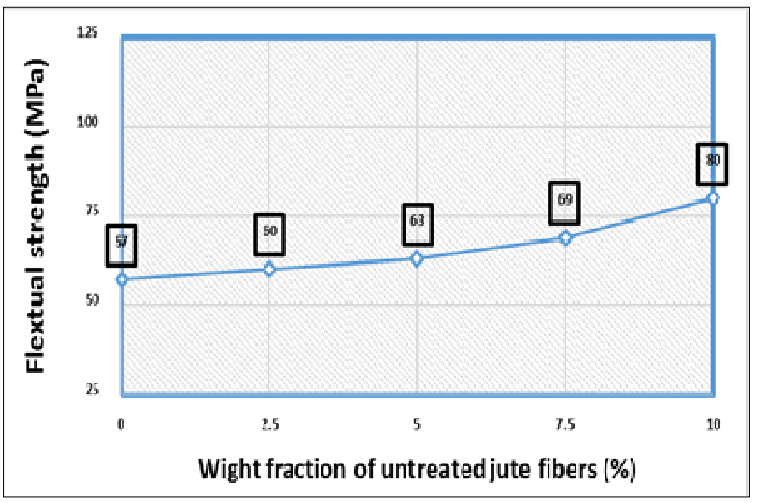

Fig. 7. Flexural strength verses weight fraction of untreated jute fibers.



Fig. 8. Impact strength verses weight fraction of untreated jute fibers.

In order to investigate the behavior of epoxy resin and epoxy-jute fibers composite material, stress-strain curve is necessary for this purpose. Fig. 9 shows the stress-strain curve for epoxy resin and epoxy resin reinforced with $10 \%$ jute fibers.

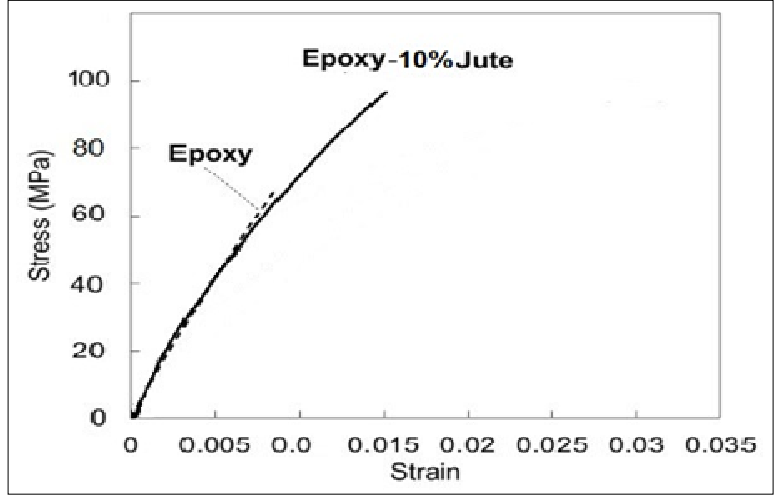

Fig. 9. Stress-strain curve for epoxy resin and epoxy resin reinforced with $\mathbf{1 0} \%$ jute fibers.

It was observed from the behavior of stressstrain curve in fig.9, the prepared composite composed of epoxy resin with $10 \%$ jute fibers exhibit high tensile strength and tensile modulus with high strain when compared with epoxy resin matrix alone.

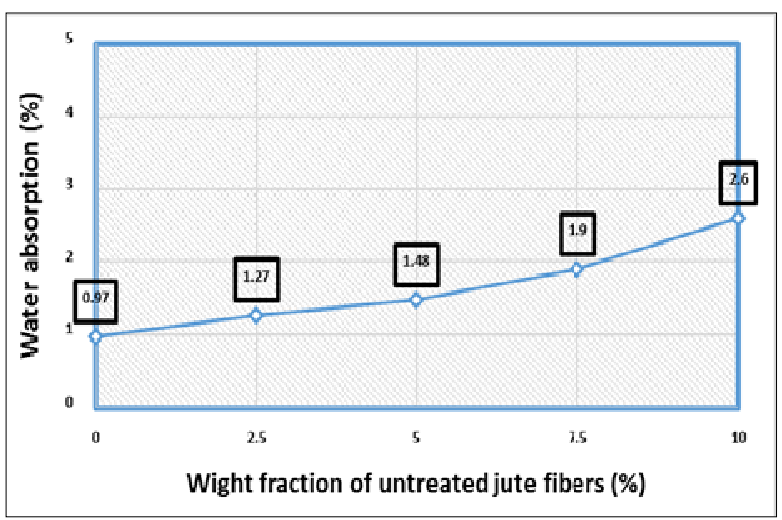

Fig. 10. Water absorption verses weight fraction of untreated jute fibers.

In addition, fig.10 shows the effect of untreated jute fibers on water absorption of epoxy resin when reinforced with the same weight fractions. The results show that, there is an obviously increased in the water absorption of epoxy resin when modified with these natural fibers and this increment increased with increasing the weight fraction of jute fibers.

The increment in the water absorption of the prepared composite is ascribed to the "hydrophilic" behavior of the jute fibers, which is mismatched with the "hydrophobic" behavior of polymer resin. This behavior lead to poor resistant to the moisture and high water absorption which result in degradation in the mechanical properties of prepared composite and the interfacial bonding between natural jute fibers and polyester resin as shown in fig. 11 . 


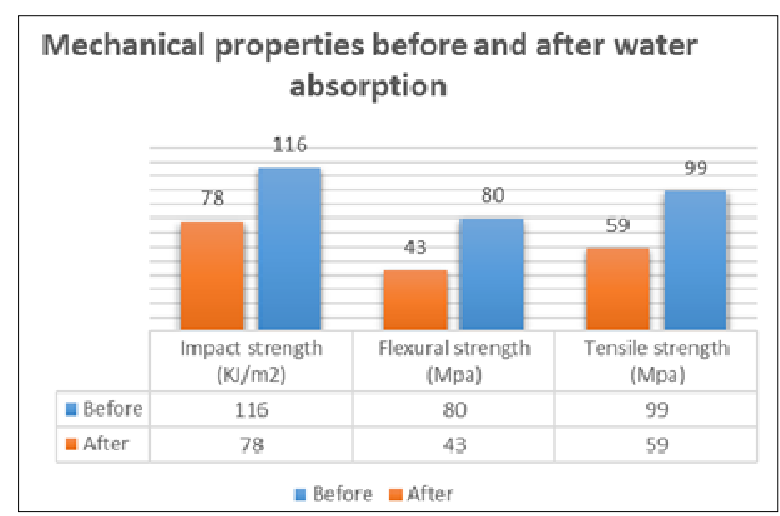

Fig. 11. Degradation in mechanical properties for $10 \%$ jute fibers reinforced epoxy resin after water absorption.

The results that obtained from fig. 11 exhibited the catastrophic effect of the water absorption of these natural fibers on the mechanical properties of epoxy resin by reducing the interfacial bonding between polymer matrix and natural fibers. For these reasons, there is an urgent need to modify the nature of these fibers by using suitable chemical treatment. Surface modification with chemical solution is the most common way for overcoming these problems. In this context, the jute fibers and walnut shell powders are treated with alkaline solution of $(\mathrm{NaOH})$ with different concentration of $(2.5,5,7.5$ and $10 \%$ respectively). The results show obviously enhancement in the mentioned mechanical properties and water absorption when fibers treated with alkaline solution and this enhancement increased with increasing the concentration of solution until $(7.5 \%)$ of $\mathrm{NaOH}$ solution related to untreated fibers as shown in the fig. 12 and fig. 13.

The improvement in the properties is attributed to the removal of lignin, waxy materials, and natural oils that covering the outside surface of the fiber cell wall as illustrated in SEM image (see fig.14) which lead to surface roughness of the natural fibers and good interfacial bonding between polymer resin and theses fibers. In addition, alkaline treatment improve fibers hydrophobic, interfacial bonding and the wettability of the natural fibers leading to decreasing in the water absorption and enhancement in the mentioned mechanical of properties of composites. On contrary, the results exhibited deteriorated in mechanical properties when fibers treated with $(10 \%)$ of $\mathrm{NaOH}$ solution, the reduction in properties is attributed to the high "alkali concentration" which causes an extra elimination of covering materials and "lignin" content that is necessary for bonding the "cellulose fibrils" with each other results in damaging of the fiber surface topography and fiber structure.

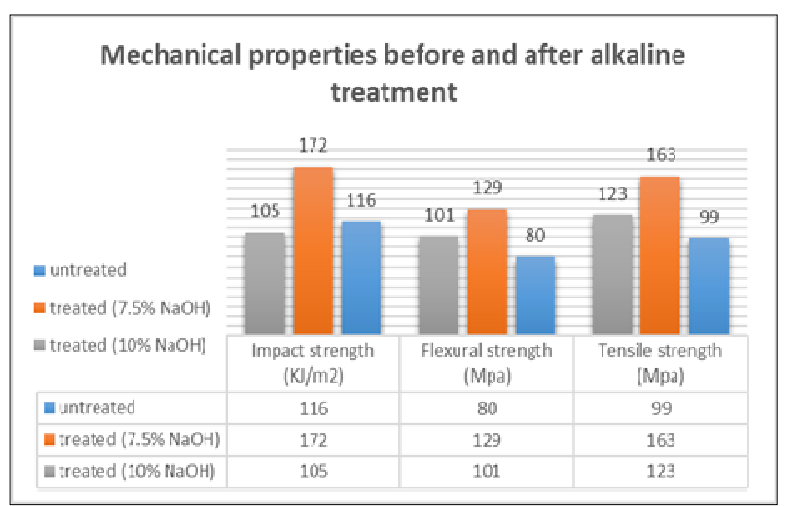

Fig. 12. Mechanical properties before and after alkaline treatment.

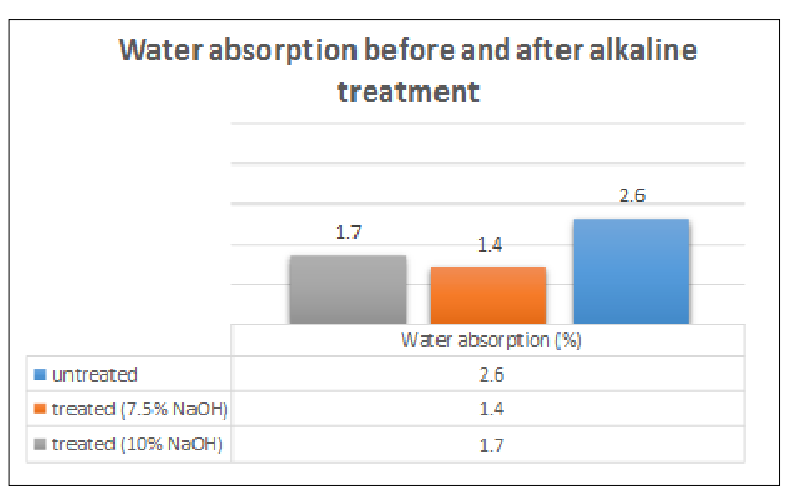

Fig. 13. Water absorption before and after alkaline treatment.

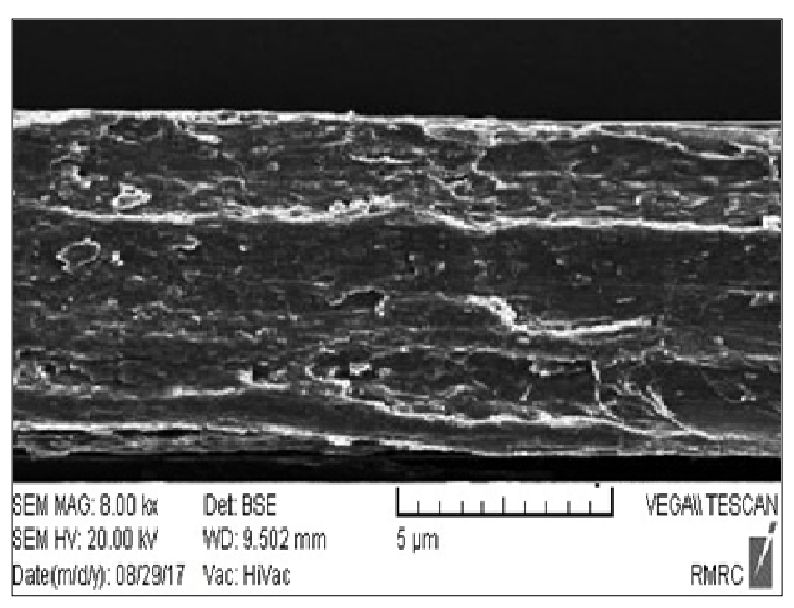

\section{A: Before alkaline treatment.}




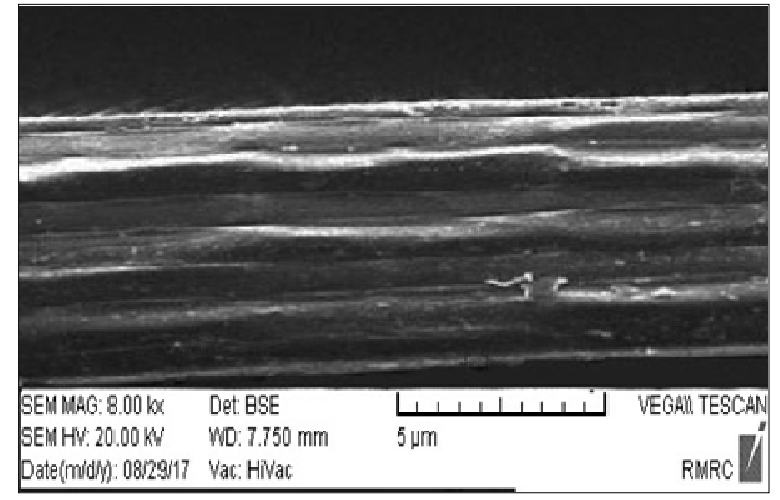

\section{B: After alkaline treatment.}

Fig. 14. SEM image of jute fibers before and after alkaline treatment.

Fig.15 and fig.16. show the influence of hybrid composite that composed of (10\%) treated jute fibers and $(5 \%)$ walnut shell powder on the mechanical properties and water absorption of epoxy resin, it was observed from obtained results, there is reasonable improvement in these properties when compared with only $(10 \%)$ treated jute fibers reinforced epoxy resin plain composite.

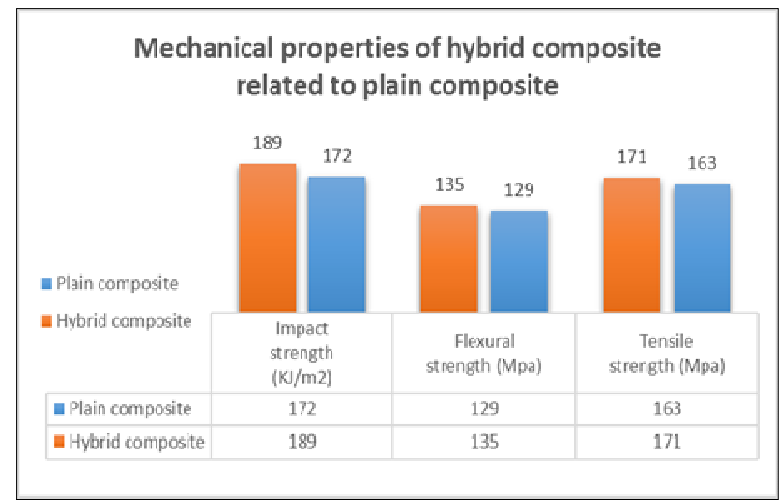

Fig. 15. Mechanical properties of the prepared hybrid composite related to plain composite.

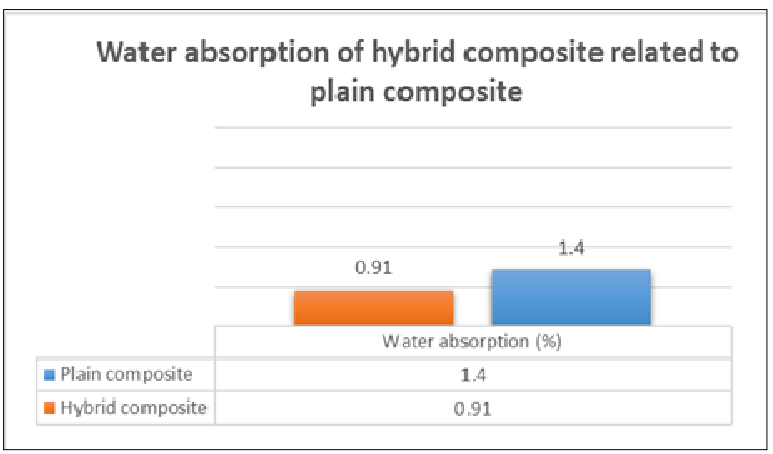

Fig. 16. Water absorption of the prepared hybrid composite related to plain composite.
The development in the properties is ascribed to the well dispersion of walnut shell powder and jute fibers in matrix as seen in fig. $17 \mathrm{~b}$ related to plain composite (fig.17a) and the compatibility between the natural walnut shell powder and epoxy resin that lead to modify the matrix by inhibiting the crack propagation and enhance the mechanical properties. In addition, the walnut shell powder plays significant role in binding the jute fibers inside the resin matrix and decrease the hydrophilicity of composites that result in reduction in the water absorption properties of epoxy resin.



Fig. 17. a. SEM image of prepared plain composite composed of $(\mathbf{1 0 \%})$ treated jute fibers reinforced epoxy resin.

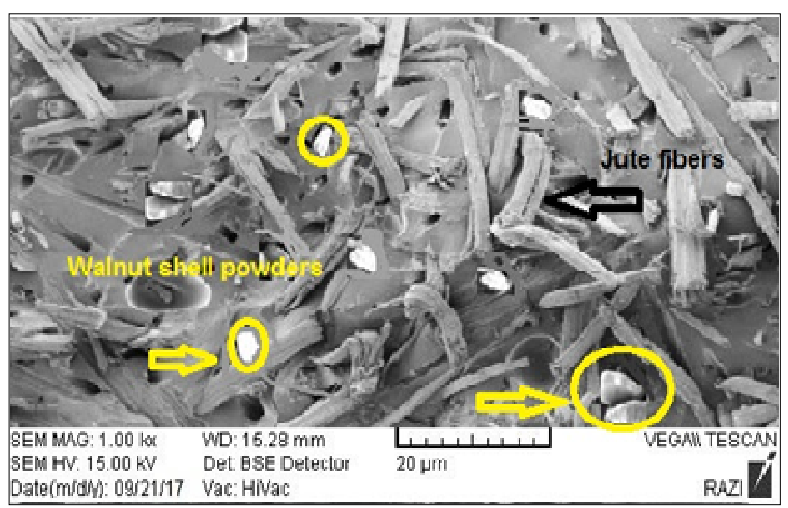

Fig. 17. b. SEM image of prepared hybrid composite composed of $(\mathbf{1 0 \%})$ treated jute fibers and $(5 \%)$ walnut shell powder reinforced epoxy resin.

\section{Conclusions}

This effort focused on the preparation of sustainable hybrid composite with minimum cost and environmental pollution by incorporating recycled natural materials in the epoxy resin. In this work, the tensile strength, impact strength, flexural strength and water absorption properties 
of epoxy resin reinforced by recycled natural materials are studied. The main conclusions can be summarized into the following:

1. The mechanical properties of epoxy resin are slightly enhanced when reinforced with different weight fraction of untreated jute fibers and this enhancement increased with increasing the weight fraction of the fibers until (10\%wt) which gives the best mechanical properties.

2. There is an obviously increased in the water absorption of epoxy resin when modified with different weight fraction of the untreated jute fibers and this increment increased with increasing the weight fraction of jute fibers.

3. The results exhibited obviously enhancement in the mentioned mechanical properties and the water absorption properties of epoxy resin reinforced with (10\%wt) jute fibers when these fibers treated with $(7.5 \%$ of $\mathrm{NaOH}$ alkaline solution) compared with untreated fibers due to the modification in the surface characterization of these natural materials.

4. The high concentration of alkaline solution result in degradation in the above mentionedproperties because of the aggressive influence of high concentration of alkaline solution on the surface topography of jute fibers.

5. The hybrid composite of epoxy resin reinforced with $(10 \% \mathrm{wt})$ recycled jute fibers and $(5 \% \mathrm{wt})$ walnut shell powder show reasonable enhancement in the abovementioned properties related to plain composite.

\section{References}

[1]Muhammad Jannah Bin Jusoh, "Studies on the properties of woven natural fibers reinforced unsaturated polyester composites", MSc thesis, 2008.

[2]Basu,G., Samanta, A.K., Ghosh, P, "Enzyme and silicone treatments on jute fiber" ,Part II. Effect on process performance during yarn making and yarn properties. Text.Inst 99, 307316, 2008.

[3]A.V. Ratna Prasad, K. Mohana, "Mechanical properties of natural fibre reinforced polyester composites: Jowar, sisal and bamboo", Materials and Design 32 (2011) 4658-4663.

[4]Allan C. Manalo, Evans Wani, Noor Azwa Zukarnain, Warna Karunasena "Effects of alkali treatment and elevated temperature on the mechanical properties of bamboo fiber polyester composites", Composites Part B 80, (2015) 73e83.

[5]Libo Yan, Nawawi Chouw, Liang Huang, Bohumil Kasal," Effect of alkali treatment on microstructure and mechanical properties of coir fibers, coir fiber reinforced polymer composites and reinforced cementitious composites", Construction and Building Materials, 112 (2016) 168-182.

[6]Grain M. Munakaampe, Shamitiba B. Kanyanga, Peter Myler, Chizyuka G. Chizyuka,"Response of natural sisal reinforced polyester composites to three-point and fourpoint bending", Procedia Manufacturing, Vol. 7, (2017), 327-332.

[7]Easwara Prasad G L, Keerthi Gowda B S, Velmurugan R, "Comparative study of impact strength characteristics of the treated and untreated sisal polyester composite", Procedia Engineering 173 ( 2017 ) 778 - 785.

[8]Sanjay M R, Arpitha G R, B Yogesha, "Study on mechanical properties of natural glass fiber reinforced polymer hybrid composites: A review", Materials Today: Proceedings 2 (2015) 2959 - 2967.

[9]D. Bazrgari, F. Moztarzadeh, A.A. SabbaghAlvani, "Mechanical properties and tribological performance of epoxy/A12O3 nanocomposite", Ceramics International, 2017.

[10] M.Ozgur Seydibeyoglu, Amar K. Mohanty, Manjusri Misra, "Fiber technology for fiber-reinforced composites", Woodhead Publishing is an imprint of Elsevier, 2017.

[11] N. Chand and M. Fahim, "Tribology of natural fiber polymer composites", Woodhead Publishing Series in Composites Science and Engineering, 2008.

[12] D3039/D3039M, "Standard test method for tensile properties of polymer matrix composite materials", American Society for Testing and Materials, Volume 15.03, 2015.

[13] D256 - 10, "Standard test methods for determining the Izod pendulum impact resistance of plastics", American Society for Testing and Materials, Volume 08.01, 2015.

[14] D790 - 10, "Standard Test Methods for Flexural Properties of Unreinforced and Reinforced Plastics and Electrical Insulating Materials", American Society for Testing and Materials, Volume 08.01, 2015. 


\title{
تأثير المعاملة القاعدية للمواد الطبيعية المعادة على خواص متراكبات راتتجات الايبوكسي
}

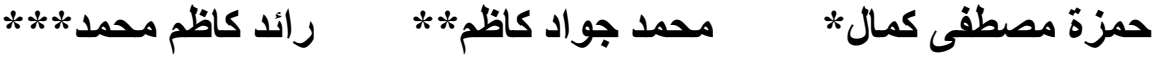

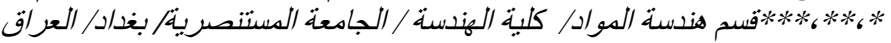

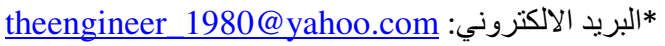 \\ moh_materials@yahoo.com البريد الالكتروني: الإني: \\ raeid1980@uomustansiriyah.edu.iq البريد الالكتروني:*** الاكيروني:
}

المو اد المتر اكبة المقو اة بالألياف و الدقائق الطبيعية تستخدم بشكل واسع بسبب خو اصها الحيوية و النوعية مثل الكثافة المنخفضة وسهولة التشغيل و الإنتاج

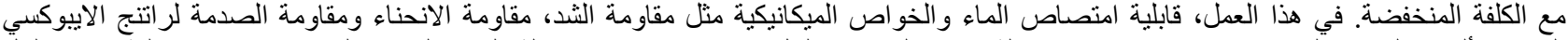

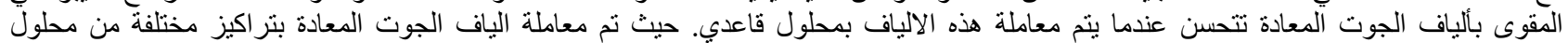

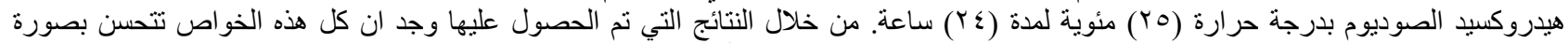

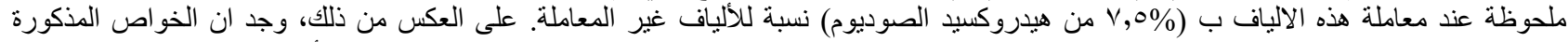

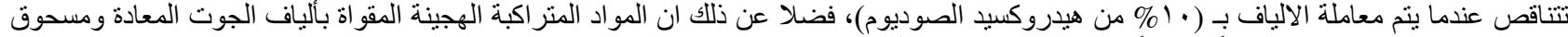

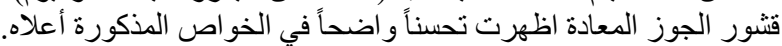

